\title{
Exploring the effects of synchronous pharyngeal electrical stimulation with swallowing carbonated water on cortical excitability in the human pharyngeal motor system
} DOI:

$10.1111 / \mathrm{nmo} .12839$

Link to publication record in Manchester Research Explorer

Citation for published version (APA):

Magara, J., Michou, E., Raginis-Zborowska, A., Inoue, M., \& Hamdy, S. (2016). Exploring the effects of synchronous pharyngeal electrical stimulation with swallowing carbonated water on cortical excitability in the human pharyngeal motor system. Neurogastroenterology and motility : the official journal of the European Gastrointestinal Motility Society, 28, 1391-1400. https://doi.org/10.1111/nmo.12839

\section{Published in:}

Neurogastroenterology and motility : the official journal of the European Gastrointestinal Motility Society

\section{Citing this paper}

Please note that where the full-text provided on Manchester Research Explorer is the Author Accepted Manuscript or Proof version this may differ from the final Published version. If citing, it is advised that you check and use the publisher's definitive version.

\section{General rights}

Copyright and moral rights for the publications made accessible in the Research Explorer are retained by the authors and/or other copyright owners and it is a condition of accessing publications that users recognise and abide by the legal requirements associated with these rights.

\section{Takedown policy}

If you believe that this document breaches copyright please refer to the University of Manchester's Takedown Procedures [http://man.ac.uk/04Y6Bo] or contact uml.scholarlycommunications@manchester.ac.uk providing relevant details, so we can investigate your claim.

\section{OPEN ACCESS}




\title{
Exploring the effects of synchronous pharyngeal electrical stimulation with swallowing carbonated water on cortical excitability in the human pharyngeal motor system
}

\author{
J. MAGARA, ${ }^{\star}, \dagger$ E. MICHOU,$\dagger$ A. RAGINIS-ZBOROWSKA,$\dagger$ M. INOUE ${ }^{\star} \&$ S. HAMDY $\dagger$ \\ *Division of Dysphagia Rehabilitation, Niigata University Graduate School of Medical and Dental Sciences, Niigata, Japan \\ $\dagger$ Centre for Gastrointestinal Sciences, Institute of Inflammation and Repair, Faculty of Medical and Human Sciences, University of \\ Manchester, Salford, UK
}

\section{Key Points}

- Excitation of human pharyngeal motor cortex can be induced by pharyngeal electrical stimulation (PES) and swallowing carbonated water $(\mathrm{CW})$. This study was undertaken to investigate the effect of synchronously combining PES with swallowing CW.

- Pharyngeal cortical and brainstem excitation was investigated using transcranial or transcutaneous magnetic stimulation (TMS).

- PES was most effective at inducing excitation in the pharyngeal motor cortex. Combination of PES and CW were less effective in producing cortical excitability but induced transient excitation in the brainstem. Our data indicate the PES may be more advantageous than combined swallowing stimuli for driving cortical changes in the swallowing system which may be useful in dysphagia rehabilitation.

\begin{abstract}
Background Previous reports have revealed that excitation of human pharyngeal motor cortex can be induced by pharyngeal electrical stimulation (PES) and swallowing carbonated water (CW). This study investigated whether combining PES with swallowing (of still water, $S W$ or $C W$ ) can potentiate this excitation in either cortical and/or brain stem areas assessed with transcranial and transcutaneous magnetic stimulation (TMS). Methods Fourteen healthy volunteers participated and were intubated with an intraluminal catheter to record pharyngeal electromyography and deliver PES. Each participant
\end{abstract}

Address for Correspondence

Shaheen Hamdy, Centre for Gastrointestinal Sciences, Institute of Inflammation and Repair, University of Manchester, Manchester Academic Health Sciences Centre (MAHSC), Salford Royal NHS Foundation Trust, Salford M6 $8 \mathrm{HD}, \mathrm{UK}$.

Tel: +44 161206 4363; fax: +44 161206 4364; e-mail: shaheen. hamdy@manchester.ac.uk

Received: 2 February 2015

Accepted for publication: 17 March 2016 underwent baseline corticopharyngeal, hand and craniobulbar motor-evoked potential (MEP) measurements. Subjects were then randomized to receive each of four 10-min interventions (PES only, Sham$P E S+C W, P E S+C W$, and PES $+S W)$. Corticobulbar, craniobulbar and hand MEPS were then remeasured for up to $60 \mathrm{~min}$ and data analyzed using ANOVA and post hoc t-tests. Key Results A two-way rmanOVa for Interventions $\times$ Time-point showed a significant corticopharyngeal interaction $(p=0.010)$. One-way ANOVA with post hoc t-tests indicated significant cortical changes with PES only at $45(p=0.038)$ and $60 \mathrm{~min}(p=0.023)$ and ShamPES $+C W$ immediately $(p=0.008)$ but not with PES $+C W$ or PES $+S W$. By contrast, there were immediate craniobulbar amplitude changes only with PES $+C W(p=0.020)$ which were not sustained. Conclusions \& Inferences We conclude that only PES produced long-term changes in corticopharyngeal excitability whereas combination stimuli were less effective. Our data suggest that PES alone rather than in combination, may be better for the patients who have difficulty in performing voluntary swallows. 
Keywords carbonated water, neurorehabilitation, pharyngeal electrical stimulation, transcranial magnetic stimulation.

\section{INTRODUCTION}

Oropharyngeal dysphagia is a common complaint reported in up to half of patients who suffer a stroke. ${ }^{1,2}$ The complications of dysphagia include aspiration pneumonia, malnutrition, and prolonged hospital stay. ${ }^{1,3-5}$ Although clinical practice to manage dysphagic stroke is usually implemented in the acute period, ${ }^{6}$ these traditional procedures such as behavioral adaptations (e.g., modifying food consistencies, compensatory maneuvres $)^{7}$ are often applied in a variable manner across institutions and their efficacy is controversial and lacks high quality evidence. ${ }^{8}$

Against this background, there has been increasing interest in the area of neuroplasticity, and how this concept can be applied therapeutically to the central nervous system to promote functional recovery. In the field of swallowing, after acute hemispheric dysphagic stroke, recovery of swallowing function appears to be in part related to neuroplasticity; that is, enlargement of the cortical representation of the pharyngeal motor region in the unaffected hemisphere. ${ }^{9,10}$ This enhancement in excitability and organization of the human pharyngeal motor cortex is induced effectively by pharyngeal electrical stimulation (PES). ${ }^{11}$ The application of a single 10 min session of PES can drive shortterm (1-h) excitation of the swallowing motor system ${ }^{12}$ in healthy participants; moreover, similar effects on corticobulbar excitability have been demonstrated in stroke patients. ${ }^{12,13}$

Promoting the application of sensory stimulation with the texture or chemoesthetic properties of the bolus can also improve swallowing performance. An example of this is carbonation of liquids. The conversion of $\mathrm{CO}_{2}$ to carbonic acid in carbonated water $(\mathrm{CW})$ leads to the activation of oropharyngeal nociceptors ${ }^{14,15}$, which excites neurons involved in signaling somatosensory inputs. ${ }^{14,16,17}$ Several existing studies have reported the positive effect of carbonation not only on swallowing behavior during swallowing carbonated bolus ${ }^{18-20}$ but also on subsequent swallowing movement. ${ }^{21}$ Recently, it has been revealed that swallowing a carbonated solution provokes increases in (pharyngeal) cortical excitability, ${ }^{22}$ which also implies that it can induce neuroplasticity in sensorimotor cortex.

Activity changing across the cortex associated with acquisition and consolidation of motor skill, which is a driver of neuroplasticity, has been well established in both human ${ }^{23,24}$ and animal studies. ${ }^{25,26}$ This motor learning increases brain excitability not only in primary motor cortex but also in somatosensory cortex depending on the learning stage. ${ }^{26,27}$ Cortical activation of somatosensory cortex has been reported during volitional swallowing movement, ${ }^{28-32}$ which is considered as a sensory feedback to regulate deglutition. ${ }^{28}$ These facts presuppose the possibility that swallowing movement with peripheral oropharyngeal sensory input can produce physiologically measurable effects on swallowing function.

This study is aimed to investigate whether the combination of swallowing movement and two different sensory stimuli (carbonation and PES) induces summative excitation both in the pharyngeal cortical area and brainstem in order to promote more practical rehabilitation for dysphagic patients. The cerebral and bulbar changes were investigated with the application of transcranial magnetic stimulation (TMS) pulses over the cortical pharyngeal areas, which are represented bilaterally in the motor cortex, and transcutaneous magnetic stimulation (TMS) over the supraorbital nerve, which triggers quantifiable reflex responses which are thought to originate in the brainstem. ${ }^{33}$ We performed these TMS measures of cortico- and craniobulbar excitability before and after various combinations of sensory interventions mentioned above. ${ }^{9,34}$ Our hypothesis was that combined PES and swallowing CW would produce greater cortical excitation in the pharyngeal motor system than either of the two approaches alone.

\section{MATERIALS AND METHODS}

\section{Recruitment and selection}

Fourteen healthy volunteers (11 males, age range 19-35 years, mean \pm SD: $27.5 \pm 5.1$ years) were recruited to complete the study. The exclusion criteria included history of epilepsy; cardiac pacemaker; previous brain or ear, nose, and throat surgery; prior history of swallowing problems; neurological disease; pregnancy; metal in the head or eyes; or intake of medication that could affect the central nervous system. This study was ethically approved by the NHS Research Ethics Committee in England and Wales. All experiments were undertaken in the clinical laboratories of the Gastrointestinal Sciences at Salford Royal NHS, England, in accordance with the Code of Ethics of the World Medical Association (Declaration of Helsinki).

\section{Pharyngeal electrical stimulation}

The same intraluminal catheter (Gaeltec Ltd, Dunvegan, Isle of Skye) used for electromyography (EMG) recordings (see below) was used for pharyngeal stimulation when connected to an electrical stimulator (Digitimer model DS7; Welwyn-Garden City, Herts, UK) and a trigger generator (Digitimer Neurology 
system), allowing measurements of an individual's sensory and maximal thresholds. The tolerated PES intensity for each patient was predetermined according to the first perceived sensation and pain threshold (the point when pharyngeal sensation became uncomfortable), which were calculated from an average of three trials. The PES $(0.2-\mathrm{ms}$ pulses, $280 \mathrm{~V})$ was delivered at a set frequency $(5 \mathrm{~Hz})$, intensity $(75 \%$ of maximal tolerated), and duration $(10 \mathrm{~min})$, which have been reported as the most effective parameters for PES. ${ }^{12}$

During sham pharyngeal stimulation, the same steps for determining the pharyngeal stimulation intensity were undertaken although the constant current generator was switched off and the intraluminal pharyngeal catheter was retained in the pharynx during the intervention.

\section{Carbonated and still water solutions}

The level of carbonation in the prepared carbonated solutions was standardized by adding $8 \mathrm{mg}$ of $\mathrm{CO}_{2}$ from a canister in 1-L water in a commercially available soda maker (iSi, Siphon Soda-Seltzer maker ${ }^{\mathcal{O}}$, iSi North America Inc., West Fairfield, NJ, USA), which keeps the water under constant temperature $\left(6^{\circ} \mathrm{C}\right), \mathrm{pH}(4.1)$, and pressure ( 60 bars/900 psi resulting in nine bars working pressure in a 1-L bottle). ${ }^{20,22}$ To control for temperature, the still water (SW) was also kept at $6{ }^{\circ} \mathrm{C}$ to match the temperature of the $\mathrm{CW}$. The liquid solutions were then infused into the subject's mouth with single use plastic syringes and manual injection of $5 \mathrm{~mL}$ boluses down a small plastic single-use tube. As each carbonated (or SW) bolus was delivered into the mouth, the participants were asked to swallow on command to a visual cue which was a green circle appearing every $15 \mathrm{~s}$ on a laptop monitor using a commercial presentation software (Powerpoint2010; Microsoft Corporation, Redmond, WA, USA) placed in front of each volunteer. This was performed for $10 \mathrm{~min}$, swallowing $5 \mathrm{~mL}$ boluses every $15 \mathrm{~s}$ (or 40 swallows).

\section{Pharyngeal motor-evoked potentials and thenar motor-evoked potentials}

Subjects were required to swallow transnasally a $3.2 \mathrm{~mm}$ diameter intraluminal catheter (Gaeltec Ltd), which houses a pair of bipolar platinum ring electrodes that are positioned in the pharynx to record EMG traces of the pharyngeal motor-evoked potentials (PMEP) induced by a single pulse of TMS over the pharyngeal motor cortex (the details about TMS are described below). An earth wire was connected to a skin electrode sited over the upper part of one of the sternocleidomastoid muscles in the neck.

As a control, thenar EMG from the abductor pollicis brevis (APB) muscle contralateral to the hemisphere giving the largest EMG of PMEP was also recorded by TMS. A pair of gel electrodes (H69P; Tyco Healthcare, Gosport, UK) was placed on the hand opposite the side of the brain, evoking the largest pharyngeal response to record the thenar motor-evoked potentials (TMEPs). An additional earth was connected to a skin electrode sited over a bony prominence on the wrist.

In order to record both muscle MEPs, the relevant electrodes were connected to a preamplifier (CED 1902; Cambridge Electronic Design, Cambridge, UK) with high- and low-pass filter settings of $200 \mathrm{~Hz}$ and $2 \mathrm{kHz}$, respectively, via connecting cables. Response signals were processed through a $50-/ 60-\mathrm{Hz}$ noise eliminator (HumBug; Quest Scientific, North Vancouver, BC, Canada) to remove any unnecessary electrical interference and collected through a laboratory interface (CED micro 1401; Cambridge Electronic Design) at a sampling rate of $5 \mathrm{kHz}$ and recorded using Signal software (ver. 2.13; Cambridge Electronic Design) running on a personal computer.

\section{Single-pulse transcranial/cutaneous magnetic stimulation}

Corticobulbar responses Focal TMS pulses were delivered using a figure of-eight-shaped magnetic coil (outer diameter, $70 \mathrm{~mm}$ ) for corticobulbar stimulation connected to a Magstim 200 (Magstim Company, Whitland, UK), which produces a maximum output of $2.2 \mathrm{~T}^{9}$. Single-pulse TMS was used at the start of each study to determine the strongest pharyngeal cortical projection and to determine the optimal coil positions for recording PMEPs (the resting motor hot spots) over both hemispheres. The resting motor threshold (rMT) was identified at this site using single pulses of stimulation to achieve PMEPs greater than $20 \mu \mathrm{V}$ in at least five of 10 trials. The pharyngeal motor cortex which produced the largest amplitude of PMEPs, at the lowest threshold, was defined as the dominant pharyngeal hemisphere. ${ }^{13,35}$

Corticospinal thenar responses The rMT for the APB muscle was measured at hand motor area local and adjacent to dominant pharyngeal hemisphere using single pulses of TMS to induce TMEPs responses greater than $100 \mu \mathrm{V}$ on at least five of 10 consecutive stimulations.

Craniobulbar reflexes In order to examine potential changes in brainstem reflexes, trigeminal nerve stimulation was performed using a smaller figure-of-eight TMS coil $(50 \mathrm{~mm})$ placed over the right supraorbital branch of the trigeminal nerve. ${ }^{12,33}$ The right side was chosen as this appears to give the most reliable recordings. The reflex EMG responses recorded from pharyngeal musculature following stimulating the nerve are regarded as originating from brainstem neurons via the brainstem swallowing center. ${ }^{33}$ Eliciting quantifiable EMG responses in at least five of 10 trials were defined as the MT stimulus intensity for the nerve.

\section{Protocols}

Subjects were randomized to attend on four separate occasions at least 3 days apart. The algorithm for the study is shown as Fig. 1.

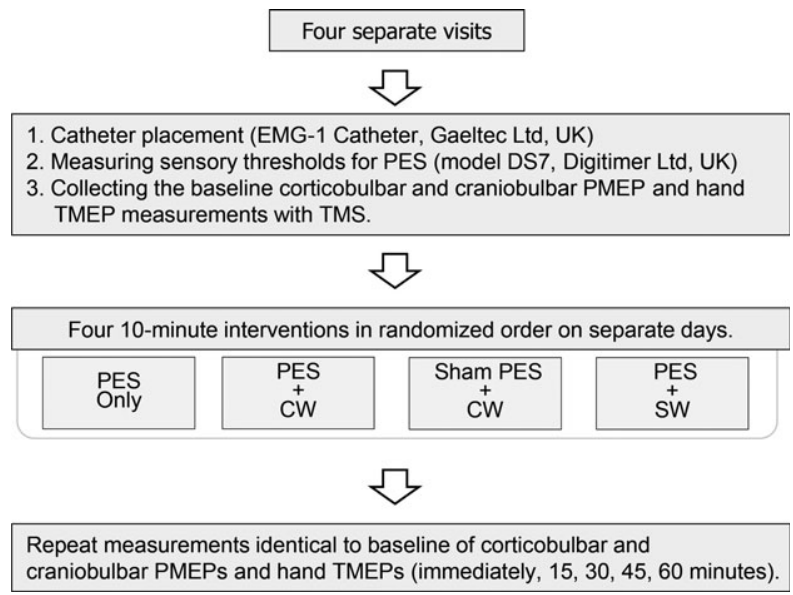

Figure 1 Flowchart summarizing the experimental protocol. PMEPs, pharyngeal motor-evoked potentials; TMEPs, thenar motor-evoked potentials. 
After swallowing the pharyngeal EMG catheter, sensory thresholds with PES were then recorded. Baseline MEPs amplitudes were assessed by delivering a set of 20 single pluses of TMS at $120 \%$ of MT for over dominant and non-dominant pharyngeal hemispheres and thenar (hand) motor cortex and at $110 \%$ of MT for craniobulbar reflexes.

Following baseline MEPs measurements, subjects received each one of four interventions in a randomized order on separate days; active PES only (PES only), sham PES with swallowing CW (ShamPES+CW), active PES with swallowing CW $(\mathrm{PES}+\mathrm{CW})$, or active PES with swallowing non-carbonated solution (SW; PES+SW).

Immediately after each intervention, all subjects received a set of 10 single-pulses TMS (follow-up measurement) per site to elicit the dominant and non-dominant PMEP, hand TMEP, and craniobulbar PMEP immediately, 15, 30, 45, and $60 \mathrm{~min}$ post intervention.

\section{Statistical analysis}

Cortical and brainstem excitability outcome measurements For each site, mean latency and peak-to-peak amplitudes of MEPs for each individual were calculated. We averaged a set of 20 MEPs per subject, and site for the baseline measurement to increase the stability and reliability of the baseline control values. Post intervention data sets of 10 MEPs were also averaged for each subject for each time point and site before being used in the ANOVA analysis (see below).

The cortical datasets collected were analyzed with repeated measures analysis of variance with factors: Time-point, Intervention (PES only, ShamPES+CW, PES+CW or PES+SW), and Site (dominant vs non-dominant hemisphere for swallowing $v s$ thenar representation site (acting as control)). Post hoc analysis using paired $t$-tests with Bonferroni correction was performed if significant interactions between the factors were observed.

The craniobulbar datasets were also analyzed using repeated measures analysis of variance with factors: Time-point and
Interventions (PES only, ShamPES+CW, PES+CW or PES+SW). Again, post hoc analysis using paired $t$-tests was performed if significant changes are observed.

A $p$-value of less than 0.05 was taken as a measure of statistical significance and all data are expressed as mean \pm SEM. Statistical analyses were performed using SPSS (IBM SPSS Statistics 20; IBM, Armonk, NY, USA).

\section{RESULTS}

In all 14 healthy volunteers, simultaneous combining PES with swallowing solutions were tolerated well without any adverse effects.

\section{Cortical hotspot mapping, resting motor thresholds and baseline TMS}

During single-pulse TMS mapping, eight of fourteen subjects showed stronger dominant pharyngeal hemisphere representation over their right hemisphere while the other six subjects had dominant pharyngeal projections over their left hemisphere. The mean distances from the cranial vertex to the motor hot spots were: dominant pharyngeal hemisphere, $2.7 \pm 0.2 \mathrm{~cm}$ mediolateral and $4.0 \pm 0.2 \mathrm{~cm}$ anteroposterior; non-dominant pharyngeal hemisphere, $2.6 \pm 0.3 \mathrm{~cm}$ mediolateral and $3.8 \pm 0.3 \mathrm{~cm}$ anteroposterior; and thenar motor cortex representation, $0.9 \pm 0.2 \mathrm{~cm}$ mediolateral and $1.8 \pm 0.3 \mathrm{~cm}$ anteroposterior. Mean $\mathrm{rMT}$, and baseline amplitude and latency for dominant, non-dominant pharyngeal PMEP and hand TMEP are shown in Table 1.

\begin{tabular}{|c|c|c|c|c|}
\hline & PES only & ShamPES+CW & $\mathrm{PES}+\mathrm{CW}$ & PES+SW \\
\hline \multicolumn{5}{|l|}{ rMT (stimulator output, \%) } \\
\hline Dominant PMEP & $57 \pm 2$ & $55 \pm 2$ & $57 \pm 2$ & $58 \pm 2$ \\
\hline Non-dominant PMEP & $61 \pm 3$ & $61 \pm 2$ & $60 \pm 2$ & $61 \pm 2$ \\
\hline TMEP & $36 \pm 2$ & $35 \pm 2$ & $35 \pm 1$ & $35 \pm 2$ \\
\hline Craniobulbar PMEP & $43 \pm 3$ & $42 \pm 3$ & $43 \pm 3$ & $43 \pm 3$ \\
\hline \multicolumn{5}{|l|}{ Amplitude $(\mu \mathrm{V})$} \\
\hline Dominant PMEP & $79.8 \pm 9.8$ & $77.5 \pm 6.6$ & $76.6 \pm 7.2$ & $78.4 \pm 7.5$ \\
\hline Non-dominant PMEP & $71.6 \pm 7.5$ & $70.2 \pm 9.5$ & $75.0 \pm 11.0$ & $72.1 \pm 9.3$ \\
\hline TMEP & $536 \pm 78$ & $524 \pm 84$ & $524 \pm 74$ & $603 \pm 91$ \\
\hline $\begin{array}{l}\text { Craniobulbar PMEP (early } \\
\text { response) }\end{array}$ & $26.1 \pm 2.7$ & $30.0 \pm 3.7$ & $22.1 \pm 1.2$ & $26.4 \pm 2.8$ \\
\hline $\begin{array}{l}\text { Craniobulbar PMEP (late } \\
\text { response) }\end{array}$ & $30.7 \pm 2.6$ & $35.6 \pm 5.5$ & $29.8 \pm 3.7$ & $32.7 \pm 2.7$ \\
\hline \multicolumn{5}{|l|}{ Latency $(\mathrm{ms})$} \\
\hline Dominant PMEP & $9.29 \pm 0.40$ & $9.40 \pm 0.42$ & $9.26 \pm 0.35$ & $9.49 \pm 0.56$ \\
\hline Non-dominant PMEP & $9.73 \pm 0.49$ & $9.36 \pm 0.50$ & $9.05 \pm 0.46$ & $9.42 \pm 0.43$ \\
\hline TMEP & $21.5 \pm 0.4$ & $21.2 \pm 0.4$ & $21.6 \pm 0.4$ & $21.1 \pm 0.3$ \\
\hline $\begin{array}{l}\text { Craniobulbar PMEP (early } \\
\text { response) }\end{array}$ & $23.8 \pm 0.6$ & $23.1 \pm 0.4$ & $24.0 \pm 0.7$ & $23.6 \pm 0.6$ \\
\hline $\begin{array}{l}\text { Craniobulbar PMEP (late } \\
\text { response) }\end{array}$ & $54.4 \pm 2.4$ & $52.3 \pm 1.6$ & $55.2 \pm 2.1$ & $56.1 \pm 2.3$ \\
\hline
\end{tabular}

rMT, resting motor threshold; MEP, motor-evoked potential; PES, pharyngeal electrical stimulation; CW, carbonated water; SW, PMEP, pharyngeal motor-evoked potentials; TMEP, thenar motor-evoked potentials.
Table 1 Data of baseline measurement of corticobulbar and craniobulbar rMT, MEP amplitudes, and latencies and stimulation intensities used for each combined interventions (mean \pm SEM) 


\section{Craniobulbar hotspot mapping, resting motor thresholds, and baseline TMS}

Supraorbital nerve stimulation evoked early and late EMG pharyngeal responses, which were usually polyphasic. Because the early response reflects a more direct reflex output from the brainstem, this was used for further analysis. We found that $3 / 14$ subjects lacked the early response so only 11 data sets were analyzed. The mean distances from the nasion to the site of trigeminal nerve stimulation were $4.6 \pm 0.3 \mathrm{~cm}$ lateral and $7.0 \pm 0.1 \mathrm{~cm}$ upper. The mean $\mathrm{rMT}$ used for trigeminal nerve stimulation and both amplitude and latency of early and late responses at baseline mesurement were shown in Table 1.

Baseline
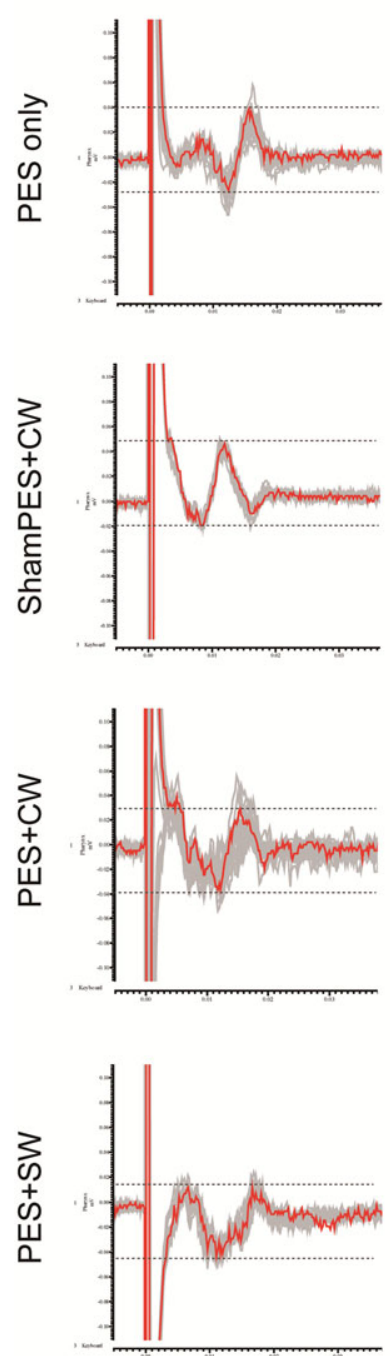

Immediately
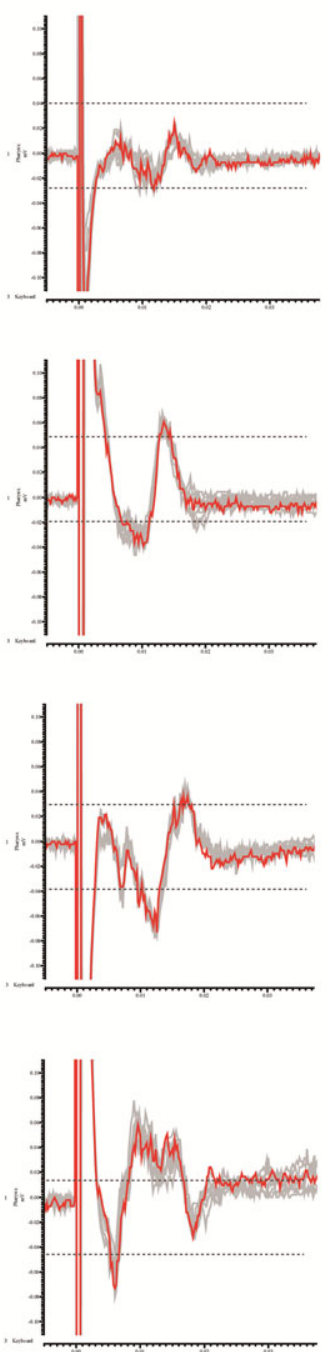

\section{Effects of the swallowing interventions on cortical excitability}

Examples of PMEPs from the dominant hemisphere of a representative participant across time for the four interventions are shown in Fig. 2. Three way rmANova comparing pharyngeal MEP amplitude changes for Time-point $\times$ Site $\times$ interventions revealed the significant interaction $\left(F_{1,13}=9.601, p=0.008\right)$. Further two way repeated measures ANOVA in the dominant hemisphere for Interventions $\times$ Time-point showed a significant interaction $\left(F_{1,13}=8.953, p=0.010\right)$. One-way ANOVA for each interventions indicated significant changes for PES only $(p<0.010)$ and ShamPES+CW $(p=0.012)$ but not for PES+CW or PES+SW over time.

30
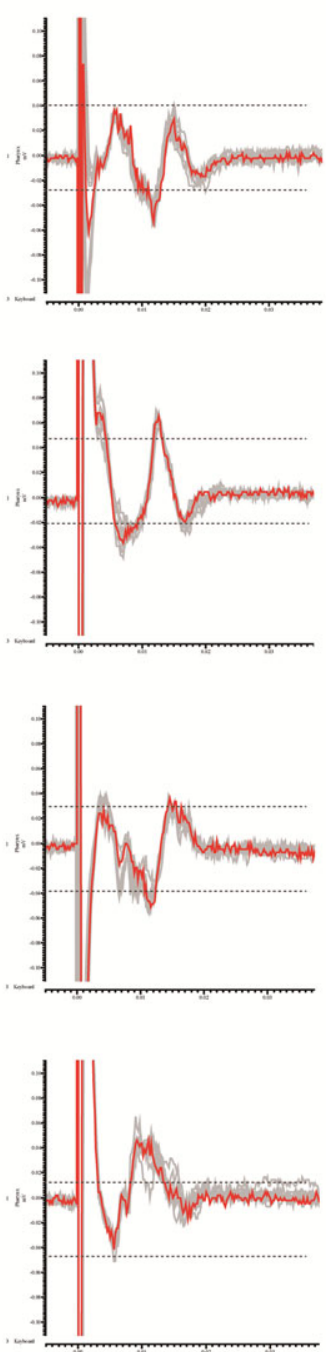

60
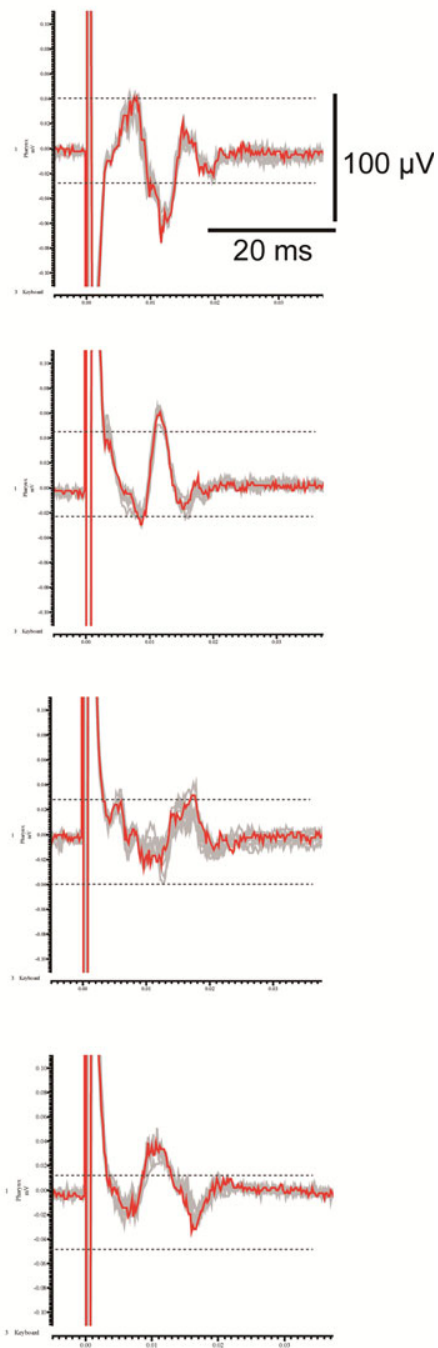

Figure 2 Representative PMEP data traces from an individual participant at each time point. For visual purposes, responses from the intermediate time points 15 and 45 min following the interventions have been removed. Trace clusters for each intervention are composed of 10 overdrawn responses for baseline and 10 waveforms for immediate, 30 and $60 \mathrm{~min}$. Horizontal dashed lines in each data set represent peak difference of PMEP amplitude at the baseline measurement to help visualise any follow-up amplitude changes. 
Subsequent post hoc $t$-tests comparing the baseline showed the main increase took place at the immediate follow-up for Sham PES+CW $(p=0.008)$ and at 45 $(p=0.038)$ and $60 \mathrm{~min}(p=0.023)$ for the PES only intervention (Fig. 3). No significant differences were

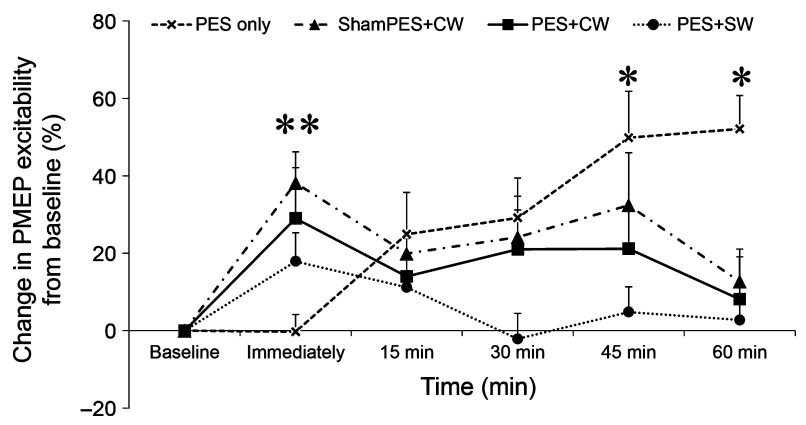

Figure 3 Changes in excitability to interventions with PES and swallowing in the dominant pharyngeal motor cortex. The data were normalized to percentage change from baseline. Significant changes for PES only (cross $\mathrm{x}$ ) and ShamPES+CW (triangle $\mathbf{A}$ ) were seen but not for PES+CW (square - or PES+SW (circle over time. Subsequent post hoc $t$-tests showed increased excitability at the immediate follow-up for ShamPES+CW $(* * p<0.01)$ and at 45 and $60 \mathrm{~min}$ for the PES only intervention $(* p<0.05)$.

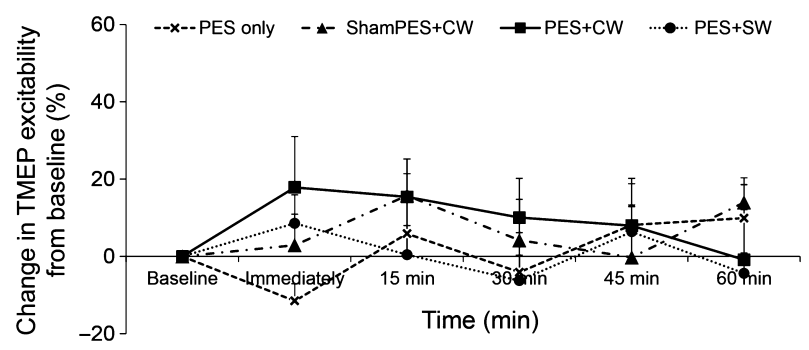

Figure 4 Changes in excitability to interventions in hand motor cortex area. The data were normalized to percentage change from baseline. No significant differences were observed for the changes in cortical excitability of the hand cortical representation across the four different interventions and for each time point as tested with ANOVA (PES only, $\mathrm{x}$; ShamPES+CW, $\mathbf{\Delta}$; PES+CW, $\mathbf{\square}$; PES+SW, observed for the changes in cortical excitability in hand cortical representation (Fig. 4). There were no significant latency interaction effects (Table 2).

\section{Effects of swallowing interventions on craniobulbar excitability}

Two way rmANOva in the early response with factors of Interventions $\times$ Time-point was non-significant $\left(F_{15,150}=0.561, p=0.900\right)$. However, one-way ANOvA for each intervention comparing excitability in the brainstem circuitry indicated significant amplitude changes only for PES+CW $\left(F_{1,10}=7.710, p=0.020\right)$ and subsequent post hoc $t$-tests demonstrated that this MEP increase was mainly at the immediate follow-up time point $(p=0.020)$ (Fig. 5). There were no significant interaction effects regarding latency (Table 2).

\section{DISCUSSION}

Our study has shown that, in contrast to our original hypothesis, combining differing sensory interventions in a simultaneous manner does not impart additional benefits in the central swallowing motor network, as measured with TMS and motor-evoked responses from the pharyngeal cortex. Rather, the most consistent effects on corticopharyngeal pathways were with giving a single sensory stimulation intervention, in the case of this study, with PES. These findings are of interest to those involved in considering therapeutic approaches in the rehabilitation of dysphagia after neurologic injury and therefore merit further discussion.

\section{Changes in the corticobulbar neural circuit}

In considering the effects of swallowing liquids, ShamPES+CW showed a short-lived but significant increase in cortical excitability immediately after the

\begin{tabular}{lllll}
\hline & PES only & ShamPES+CW & PES+CW & PES+SW \\
\hline Corticobulbar & & & & \\
Baseline & $9.29 \pm 0.40$ & $9.40 \pm 0.42$ & $9.26 \pm 0.35$ & $9.49 \pm 0.56$ \\
Immediately & $8.93 \pm 0.40$ & $9.71 \pm 0.40$ & $9.23 \pm 0.39$ & $9.64 \pm 0.62$ \\
15 min & $9.20 \pm 0.40$ & $9.47 \pm 0.39$ & $9.12 \pm 0.38$ & $9.43 \pm 0.54$ \\
30 min & $9.20 \pm 0.43$ & $9.43 \pm 0.41$ & $9.10 \pm 0.35$ & $9.68 \pm 0.56$ \\
45 min & $9.22 \pm 0.37$ & $9.49 \pm 0.36$ & $9.04 \pm 0.30$ & $9.48 \pm 0.56$ \\
60 min & $9.25 \pm 0.42$ & $9.34 \pm 0.32$ & $9.26 \pm 0.32$ & $9.48 \pm 0.56$ \\
Craniobulbar (early response) & & & \\
Baseline & $23.8 \pm 0.6$ & $23.1 \pm 0.4$ & $24.0 \pm 0.7$ & $23.6 \pm 0.6$ \\
Immediately & $23.2 \pm 0.6$ & $23.4 \pm 0.6$ & $24.1 \pm 0.7$ & $23.8 \pm 0.7$ \\
15 min & $23.8 \pm 0.6$ & $23.3 \pm 0.4$ & $24.1 \pm 0.5$ & $24.2 \pm 0.7$ \\
30 min & $22.8 \pm 1.0$ & $22.6 \pm 0.7$ & $23.5 \pm 0.9$ & $23.7 \pm 0.6$ \\
45 min & $24.0 \pm 0.8$ & $23.9 \pm 0.6$ & $23.8 \pm 0.6$ & $23.1 \pm 0.9$ \\
60 min & $23.8 \pm 0.5$ & $22.5 \pm 0.7$ & $23.8 \pm 0.7$ & $23.7 \pm 0.9$ \\
\hline
\end{tabular}

Table 2 Table of dominant corticobulbar and craniobulbar-evoked response latencies (in ms) for PMEPs after PES only, Sham$\mathrm{PES}+\mathrm{CW}, \mathrm{PES}+\mathrm{CW}$, and PES+SW (mean \pm SEM)

See Table 1 for abbreviations. 


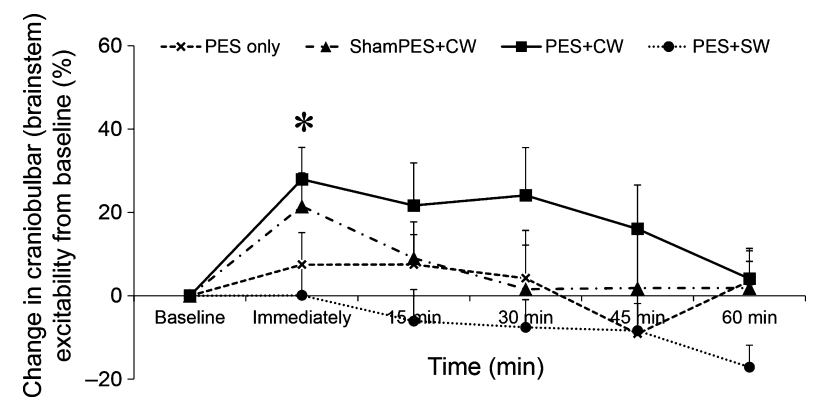

Figure 5 Changes in excitability to interventions with PES and swallowing in the brainstem circuitry. The data were normalized to percentage change from baseline. There was significant amplitude changes only for PES $+\mathrm{CW}$ (square $\mathbf{0})(p=0.020)$ and subsequent post hoc $t$-tests demonstrated that this MEP increase was mainly at the immediate follow-up ( $\left.{ }^{*} p<0.05\right)$ (PES only, $\mathrm{x}$; ShamPES+CW, $\boldsymbol{\Delta}$ $\mathrm{PES}+\mathrm{SW}, \mathbf{0}$

intervention, whereas when combined, both PES+CW and PES+SW produced little or no effect. Previous studies comparing the independent effects of swallowing water or PES revealed that swallowing just water can provoke early facilitation of corticobulbar projections. $^{36,37}$ The authors ${ }^{36}$ speculated that these effects were mainly driven through lower level circuitry with changes in brainstem reflexes but were not sustained. By contrast, in that same study, PES alone evoked a build up of cortical excitability, which lasted 45-60 min and was not associated with increases in brainstem reflex activity. Our current findings on the effects of swallowing without PES are consistent with this observation, as seen in the ShamPES+CW effects, where brainstem reflexes were again slightly increased. Moreover, PES alone produced the same slower build up in cortical excitability over the hour without craniobulbar changes. Less clear is why the combination of PES with either CW or SW had no discernible effect on cortical excitability. When PES is performed alone, we asked participants to try to not swallow during the intervention. When swallowing does occur simultaneously, as with the combination interventions, there will be movement around the electrodes in the throat which may reduce contact of the pharyngeal electrical stimulus and perhaps result in a reduced central effect. Equally it is possible that the additional swallowing activity causes some fatigue of the cortical swallowing system, which provoked a level of inhibition in cortical excitability reducing any long-term effect. Considering the effect of swallowing solutions, previous reports have shown that there is an immediate increase in excitability without long-term changes when applying either room temperature ${ }^{36}$ or cold water $\left(4-6^{\circ} \mathrm{C}\right)^{22,37}$ on pharyngeal cortex. Thus, it would appear that cold water swallowing alone is not a strong inducer of cortical excitation despite cold stimulation being an established method of the rehabilitation for dysphagia patient. ${ }^{38}$ By contrast, we have also previously described a cortical effect when swallowing CW alone. ${ }^{22}$ It is therefore difficult to explain why combine with PES might block this effect; one can only speculate that combining these stimuli may be more nociceptive or unpleasant and that this is somehow more maladaptive in respect of driving increases in cortical pharyngeal excitability.

As reported before, ${ }^{11,12}$ the effect of active PES alone produced significant and sustained changes up to $60 \mathrm{~min}$ following $10 \mathrm{~min} 5 \mathrm{~Hz}, 75 \%$ intensity stimulation although some differences were observed in the size of the excitability changes seen in our current experiment. By contrast, the combination of a motor task (swallowing) with functional electrical stimulation (PES) was ineffective. Earlier research regarding hand and leg rehabilitation using motor training with sensory stimulation suggested that that this type of combined stimuli can induce larger changes in excitability and/or neuroplasticity in motor cortex ${ }^{39-41}$, whereas tongue protrusion motor training, which alone produces measured neuroplasticity and successful performance, was less effective on motor cortex with nociceptive sensory stimulation. ${ }^{42}$ These may be due to the differences in the neural systems between spinal and cranial nerves or in the type of experimental noxious stimulus. It seems reasonable to infer that swallowing motor movement innervated by cranial (vagus and glossopharyngeal) nerves, as with the tongue training, may block or reduce the long-term effect of PES as discussed above.

Another possible reason why the combined peripheral stimuli of PES and carbonation is less effective on cortical excitability than PES alone is that taste stimulation might directly reduce activity in the nucleus tractus solitarii (NTS), which may have led to a reduction in the activity of corticobulbar circuit and consequentially reduced PMEPs evaluated using TMS. ${ }^{37}$ Although this study lacks the data which directly indicate the correlation between cortical excitability and participant's experience of taste, unpleasantness has been described when experiencing the fizzy taste of carbonation. ${ }^{20}$

\section{Changes in craniobulbar neural circuit as the brain stem excitability}

To evaluate the excitability in the brainstem, this study used the craniobulbar supraorbital nerve stimu- 
lation using TMS as previous research studies have reported. ${ }^{33,36}$ Pharyngeal motor-evoked potential waveform produced by stimulating craniobulbar pathway shows two responses; an early response (19-30 ms) and a late $(42-72 \mathrm{~ms})$ response. ${ }^{33,36,43}$ The early response, which is thought to be a more direct brainstem reflex, is more inconsistent, ${ }^{33}$ and indeed three of fourteen participants lacked early response in this study. Considering the latency of these reflexes and comparing them with other similar loops such as the blink reflex ${ }^{44}$ it seems reasonable to infer that early response produced by stimulating the supraorbital nerve is a measure of neural activity in the brainstem although a corticobulbar pathway of this loop has been not fully excluded.

The results in this study showed significant but transient excitability changes in the brainstem early reflexes following the combining PES with $\mathrm{CW}$ but little or no changes with the other three interventions. It seems appropriate to consider that these transient changes could be attributed to the effect of swallowing CW. Swallowing carbonated liquids causes the peripheral pungent orotactile experience expressed as 'fizzy' sensation, which is received by oropharyngeal nociceptors and acidification of tissue and embedded nerve endings which occur when $\mathrm{CO}_{2}$ is hydrated to carbonic acid, ${ }^{15,45}$ and catalyzed with carbonic anhydrase; although the carbonated sensation is also modulated by the bubbles themselves. ${ }^{46}$ The primary sensory trigeminal afferent fibers on oral mucosa which receive carbonic acid project to the trigeminal subnucleus caudalis. ${ }^{15}$ Animal studies have revealed that there are rich interconnections between the spinal trigeminal nucleus and NTS, ${ }^{47}$ which also receives irritant chemical sensory input in pharyngeal via glossopharyngeal and vagus nerves. ${ }^{48}$ Oropharyngeal stimulation with carbonation may have increased neuronal activity around NTS, which resulted in the transient excitability change following the intervention of swallowing CW (with PES).

Previous human studies have demonstrated that pharyngeal cortical excitability is induced both by $5 \mathrm{~Hz}$ peripheral electrical stimulation ${ }^{12,13,49}$ or by $5 \mathrm{~Hz}$ cortical rTMS, ${ }^{35}$ whereas many animal studies have found that neural excitability in NTS is more likely to be induced (and a swallowing reflex evoked) when a relatively high frequency $(30$ or $40 \mathrm{~Hz})$ peripheral superior laryngeal nerve stimulation is applied. ${ }^{50-52}$ These data may suggest that higher frequencies of stimulation are necessary to produce NTS excitatory change. Although we cannot be certain that simultaneously combining PES with CW stimuli is similar to high frequent stimulation, PES with carbonation could be an effective modality of stimulation for the brainstem excitability given the levels of carbonic input occurring via NTS based mechanisms. Further study would be needed to investigate what stimulation modality or parameters of stimulation are able to induce brainstem excitability, which might be beneficial for the patient suffering from brainstem infarction or bulbar paralysis.

In terms of limitations of the study, while neurophysiological data were collected to gain insight into mechanism, we did not undertake investigations of swallowing behavioral changes following the interventions to assess their functional effects as observed as previous reports. ${ }^{22,53}$ Improvement of swallowing behavior such as swallowing reaction time may have occurred despite little or no increases in cortical excitability. Moreover, combining two sequential stimuli, for instance, swallowing CW immediately after PES only intervention may have produced a different result to this study. These studies will help to better understand the effect of combining peripheral stimuli or motor movement on the swallowing neural network.

In conclusion, of the four interventions applied, only PES alone was able to produce long-term changes in pharyngeal cortical excitability with combination stimuli being less effective in promoting enhanced cortical excitability. Of interest, combination stimuli did produce short-term increases in excitability in brainstem reflexes, possibly related to the additive effects of swallowing CW. Our data suggest that PES alone may be most beneficial way for the patients who have a difficulty in performing voluntary swallows.

\section{ACKNOWLEDGEMENTS}

This study was partly supported by the Neuroenterology Charitable Donation Fund based at Salford Royal Hospital, Grants-inAid for Scientific Research from the Ministry of Education, Culture, Sports, Science and Technology of Japan (no. 23415730 to J.M.), by the Strategic Young Researcher Overseas Visits Program for Accelerating Brain Circulation (no. S2504) from the Japan Society for the Promotion of Science. The study was sponsored by the University of Manchester, UK, which did not have a role in the study design, or in the collection, analysis or interpretation of data.

\section{FUNDING}

Supported by Grants-in-Aid for Scientific Research from the Ministry of Education, Culture, Sports, Science and Technology of Japan (no. 23415730), and the Strategic Young Researcher Overseas Visits Program for Accelerating Brain Circulation from the Japan Society for the Promotion of Science (no. S2504). 


\section{DISCLOSURE}

The authors declare that they have no direct conflicts of interest. $\mathrm{SH}$ is chief scientific officer and on the clinical advisory board of Phagenesis Ltd (Manchester, UK).

\section{AUTHOR CONTRIBUTION}

JM, EM and ARZ performed the experiments; JM was responsible for acquisition and analysis of data and drafting of the manuscript; IM providedcritical revision of the manuscript; SHhandled study concept design, interpretation of data, and critical revision of the manuscript.

\section{REFERENCES}

1 Finlayson O, Kapral M, Hall R, Asllani E, Selchen D, Saposnik G, Canadian Stroke Network, Stroke Outcome Research Canada (SORCan) Working Group. Risk factors, inpatient care, and outcomes of pneumonia after ischemic stroke. Neurology 2011; 77: 1338-45.

2 Martino R, Foley N, Bhogal S, Diamant N, Speechley M, Teasell R. Dysphagia after stroke: incidence, diagnosis, and pulmonary complications. Stroke 2005; 36: 2756-63.

3 Perry L, Love CP. Screening for dysphagia and aspiration in acute stroke: a systematic review. Dysphagia 2001; 16: $7-18$.

4 Altman KW, Yu GP, Schaefer SD. Consequence of dysphagia in the hospitalized patient: impact on prognosis and hospital resources. Arch Otolaryngol Head Neck Surg 2010; 136: 784-9.

5 Guyomard V, Fulcher RA, Redmayne O, Metcalf AK, Potter JF, Myint PK. Effect of dysphasia and dysphagia on inpatient mortality and hospital length of stay: a database study. I Am Geriatr Soc 2009; 57: 2101-6.

6 Carnaby G, Hankey GJ, Pizzi J. Behavioural intervention for dysphagia in acute stroke: a randomised controlled trial. Lancet Neurol 2006; 5: 31-7.

7 Rogus-Pulia N, Robbins J. Approaches to the rehabilitation of dysphagia in acute poststroke patients. Semin Speech Lang 2013; 34: 154-69.

8 Carnaby GD, Harenberg L. What is "usual care" in dysphagia rehabilitation: a survey of USA dysphagia practice patterns. Dysphagia 2013; 28: 567-74.

9 Hamdy S, Aziz Q, Rothwell JC, Singh KD, Barlow J, Hughes DG, Tallis RC, Thompson DG. The cortical topography of human swallowing musculature in health and disease. Nat Med 1996; 2: 1217-24.

10 Hamdy S, Aziz Q, Rothwell JC, Crone R, Hughes D, Tallis RC, Thompson DG. Explaining oropharyngeal dysphagia after unilateral hemispheric stroke. Lancet 1997; 350: 686-92.
11 Hamdy S, Rothwell JC, Aziz Q, Singh $\mathrm{KD}$, Thompson DG. Long-term reorganization of human motor cortex driven by short-term sensory stimulation. Nat Neurosci 1998; 1: 64-8.

12 Fraser C, Power M, Hamdy S, Rothwell J, Hobday D, Hollander I, Tyrell P, Hobson A et al. Driving plasticity in human adult motor cortex is associated with improved motor function after brain injury. Neuron 2002; 34: 831-40.

13 Jayasekeran V, Singh S, Tyrrell $\mathrm{P}$, Michou E, Jefferson S, Mistry S, Gamble E, Rothwell J et al. Adjunctive functional pharyngeal electrical stimulation reverses swallowing disability after brain lesions. Gastroenterology 2010; 138: 1737-46.

14 Dessirier JM, Simons CT, O'Mahony $\mathrm{M}$, Carstens E. The oral sensation of carbonated water: cross-desensitization by capsaicin and potentiation by amiloride. Chem Senses 2001; 26: 639-43.

15 Simons CT, Dessirier JM, Carstens MI, O'Mahony M, Carstens E. Neurobiological and psychophysical mechanisms underlying the oral sensation produced by carbonated water. J Neurosci 1999; 19: 8134-44.

16 Wise PM, Bryant B. The effect of temperature and menthol on carbonation bite. Chem Senses 2014; 39: 571-82.

17 Dessirier JM, Simons CT, Carstens MI, O'Mahony M, Carstens E. Psychophysical and neurobiological evidence that the oral sensation elicited by carbonated water is of chemogenic origin. Chem Senses 2000; 25: $277-$ 84.

18 Bulow M, Olsson R, Ekberg O. Videoradiographic analysis of how carbonated thin liquids and thickened liquids affect the physiology of swallowing in subjects with aspiration on thin liquids. Acta Radiol 2003; 44: 366-72.

19 Sdravou K, Walshe M, Dagdilelis L. Effects of carbonated liquids on oropharyngeal swallowing measures in people with neurogenic dysphagia. Dysphagia 2012; 27: 240-50.
20 Michou E, Mastan A, Ahmed S, Mistry S, Hamdy S. Examining the role of carbonation and temperature on water swallowing performance: a swallowing reaction-time study. Chem Senses 2012; 37: 799-807.

21 Morishita M, Mori S, Yamagami S, Mizutani M. Effect of carbonated beverages on pharyngeal swallowing in young individuals and elderly inpatients. Dysphagia 2014; 29: 213-22.

22 Elshukri O, Michou E, Mentz H, Hamdy S. Brain and behavioural effects of swallowing carbonated water on the human pharyngeal motor system. I Appl Physiol (1985) 2016; 120: 408-15.

23 Karni A, Meyer G, Jezzard P, Adams MM, Turner $R$, Ungerleider LG. Functional MRI evidence for adult motor cortex plasticity during motor skill learning. Nature 1995; 377: 1558.

24 Karni A, Meyer G, Rey-Hipolito C, Jezzard P, Adams MM, Turner R, Ungerleider LG. The acquisition of skilled motor performance: fast and slow experience-driven changes in primary motor cortex. Proc Natl Acad Sci USA 1998; 95: 861-8.

25 Arce FI, Lee JC, Ross CF, Sessle BJ, Hatsopoulos NG. Directional information from neuronal ensembles in the primate orofacial sensorimotor cortex. I Neurophysiol 2013; 110: 1357-69.

26 Arce-McShane FI, Hatsopoulos NG, Lee JC, Ross CF, Sessle BJ. Modulation dynamics in the orofacial sensorimotor cortex during motor skill acquisition. I Neurosci 2014; 34: 5985-97.

27 Floyer-Lea A, Matthews PM. Distinguishable brain activation networks for short- and long-term motor skill learning. I Neurophysiol 2005; 94: 512-8.

28 Martin RE, Goodyear BG, Gati JS, Menon RS. Cerebral cortical representation of automatic and volitional swallowing in humans. I Neurophysiol 2001; 85: 938-50.

29 Hamdy S, Mikulis DI, Crawley A, Xue S, Lau H, Henry S, Diamant NE. 
Cortical activation during human volitional swallowing: an eventrelated fMRI study. Am I Physiol 1999; 277: G219-25.

30 Hamdy S, Rothwell JC, Brooks DI, Bailey D, Aziz Q, Thompson DG. Identification of the cerebral loci processing human swallowing with $\mathrm{H} 2$ (15)O PET activation. I Neurophysiol 1999; 81: 1917-26.

31 Mosier K, Patel R, Liu WC, Kalnin A, Maldjian J, Baredes S. Cortical representation of swallowing in normal adults: functional implications. Laryngoscope 1999; 109: 1417-23.

32 Martin RE, MacIntosh BJ, Smith RC, Barr AM, Stevens TK, Gati JS, Menon RS. Cerebral areas processing swallowing and tongue movement are overlapping but distinct: a functional magnetic resonance imaging study. J Neurophysiol 2004; 92: 2428-43.

33 Hamdy S, Aziz Q, Rothwell JC, Hobson A, Barlow J, Thompson DG. Cranial nerve modulation of human cortical swallowing motor pathways. Am J Physiol 1997; 272: G802-8.

34 Hamdy S, Aziz Q, Rothwell JC, Power M, Singh KD, Nicholson DA, Tallis RC, Thompson DG. Recovery of swallowing after dysphagic stroke relates to functional reorganization in the intact motor cortex. Gastroenterology 1998; 115: 1104-12.

35 Jefferson S, Mistry S, Michou E, Singh S, Rothwell JC, Hamdy S. Reversal of a virtual lesion in human pharyngeal motor cortex by high frequency contralesional brain stimulation. Gastroenterology 2009; 137: 841-9, 849 e841.

36 Fraser C, Rothwell J, Power M, Hobson A, Thompson D, Hamdy S. Differential changes in human pharyngoesophageal motor excitability induced by swallowing, pharyngeal stimulation, and anesthesia. Am I Physiol Gastrointest Liver Physiol 2003; 285: G137-44.

37 Mistry S, Rothwell JC, Thompson DG, Hamdy S. Modulation of human cortical swallowing motor pathways after pleasant and aversive taste stimuli. Am I Physiol Gastrointest Liver Physiol 2006; 291: G666-71.

38 Teismann IK, Steinstrater O, Warnecke T, Suntrup S, Ringelstein EB, Pantev C, Dziewas R. Tactile thermal oral stimulation increases the cortical representation of swallowing. $B M C$ Neurosci 2009; 10: 71.

39 Barsi GI, Popovic DB, Tarkka IM, Sinkjaer T, Grey MJ. Cortical excitability changes following grasping exercise augmented with electrical stimulation. Exp Brain Res 2008; 191: $57-66$

40 Khaslavskaia S, Sinkjaer T. Motor cortex excitability following repetitive electrical stimulation of the common peroneal nerve depends on the voluntary drive. Exp Brain Res 2005; 162: 497-502.

41 Bhatt E, Nagpal A, Greer KH, Grunewald TK, Steele JL, Wiemiller JW, Lewis SM, Carey JR. Effect of finger tracking combined with electrical stimulation on brain reorganization and hand function in subjects with stroke. Exp Brain Res 2007; 182: 43547.

42 Boudreau S, Romaniello A, Wang K, Svensson P, Sessle BJ, Arendt-Nielsen $\mathrm{L}$. The effects of intra-oral pain on motor cortex neuroplasticity associated with short-term novel tongueprotrusion training in humans. Pain 2007; 132: 169-78.

43 Jayasekeran V, Rothwell J, Hamdy S. Non-invasive magnetic stimulation of the human cerebellum facilitates cortico-bulbar projections in the swallowing motor system. Neurogastroenterol Motil 2011; 23: 831e341.

44 Pellegrini JJ, Horn AK, Evinger C. The trigeminally evoked blink reflex. I. Neuronal circuits. Exp Brain Res 1995; 107: 166-80.

45 Wang YY, Chang RB, Allgood SD, Silver WL, Liman ER. A TRPA1dependent mechanism for the pun- gent sensation of weak acids. I Gen Physiol 2011; 137: 493-505.

46 Wise PM, Wolf M, Thom SR, Bryant B. The influence of bubbles on the perception carbonation bite. PLOS ONE 2013; 8: e71488.

47 Zerari-Mailly F, Buisseret P, Buisseret-Delmas C, Nosjean A. Trigemino-solitarii-facial pathway in rats. J Comp Neurol 2005; 487: 176-89.

48 Boucher Y, Simons CT, Cuellar JM, Jung SW, Carstens MI, Carstens E. Activation of brain stem neurons by irritant chemical stimulation of the throat assessed by c-fos immunohistochemistry. Exp Brain Res 2003; 148: $211-8$.

49 Jayasekeran V, Pendleton N, Holland G, Payton A, Jefferson S, Michou E, Vasant D, Ollier B. Val66Met in brain-derived neurotrophic factor affects stimulus-induced plasticity in the human pharyngeal motor cortex. Gastroenterology 2011; 141: $827-$ 36 e821-823.

50 Tsuji K, Tsujimura T, Magara J, Sakai $S$, Nakamura $Y$, Inoue $M$. Changes in the frequency of swallowing during electrical stimulation of superior laryngeal nerve in rats. Brain Res Bull 2015; 111: 53-61.

51 Miller AJ. Characteristics of the swallowing reflex induced by peripheral nerve and brain stem stimulation. Exp Neurol 1972; 34: 210-22.

52 Tsujimura $\mathrm{T}$, Tsuji $\mathrm{K}$, Magara $\mathrm{J}$, Sakai S, Suzuki T, Nakamura Y, Nozawa-Inoue K, Inoue M. Differential response properties of peripherally and cortically evoked swallows by electrical stimulation in anesthetized rats. Brain Res Bull 2016; 122: $12-8$.

53 Vasant DH, Mistry S, Michou E, Jefferson S, Rothwell JC, Hamdy S. Transcranial direct current stimulation reverses neurophysiological and behavioural effects of focal inhibition of human pharyngeal motor cortex on swallowing. I Physiol 2014; 592: 695709. 